\title{
V030 RESERVOIR CHARACTERIZATION BY USING PERMANENT DOWNHOLE GEOPHONES IN 4D SEISMIC AND MICRO- SEISMIC MONITORING APPLICATIONS
}

\author{
J.-P. DEFLANDRE ${ }^{1}$, J. LAURENT ${ }^{1}$, S. SERBUTOVIEZ ${ }^{1}, F$. HUGUET $^{2}$ and F. VERDIER ${ }^{2}$ \\ 'Institut Français du Pétrole, PO Box 311, 92506 Rueil-Malmaison, France \\ ${ }^{2}$ Gaz de France
}

\begin{abstract}
Two types of Permanent Downhole Geophones (PDG) [1,2] have been developed for use in a permanent way (several years) in oil or gas wells. These geophones were designed to be installed between the casing and the tubing (Figure 1) or, if needed, behind the casing of new wells. They can be adapted to different well completions. PDGs are suitable for two types of applications: 4D seismic measurements and microseismic monitoring.

- For 4D-seismic measurements, these downhole geophones enable the easy setting of multiazimuthal borehole seismic to perform data acquisitions in a repeatable way. Then, differential time and/or amplitude variations can be measured in the instrumented wellbore vicinity. For example, the estimation of acoustic impedance variations can be performed, after VSP data inversion, between depth levels that were instrumented with PDGs. Figure 2 shows impedance logs computed at different periods after inversion of PSV data. Variations due to gas storage can be observed at the reservoir level (impedance decreases from the left to the right of the figure).

- Installing 3-component PDGs close to the reservoir level enables the recording of microseismic events of very small magnitude (less than -1). The data obtained make it possible to locate the mechanically active zones associated with fluid injection or withdrawal. Different applications are targeted with such an equipment: control of waste fluid storage such as drilling mud with or without solid particles, water injection control, the monitoring of microseismicity associated with production. In the first case, the aim is to control the injection pressure to prevent hydraulic fracturing. In the case of water injection thermal fracturing can be induced in area where the injected fluid goes, also the monitoring of the associated acoustic activity can be used to identify these areas and by difference those which are less concerned by the injection. This can be used to optimise the injection well pattern. The last case concerns reservoir management in general.
\end{abstract}

Different wells have already been equipped - with at least up to fifteen levels in a well - to monitor gas movements in an underground gas storage reservoir. More generally, these different kinds of applications widely contribute to a better knowledge of the reservoir response and then they make it possible to optimise reservoir management.

Keywords: permanent downhole geophones, 4D seismic, repetitive seismic, active monitoring, induced microseismicity, micro-earthquakes, passive monitoring, underground gas storage, gas injection.

\section{References:}

[1] Laurent J., Naville C. and Czernichow J. (1993), Method and equipment for acoustic wave prospecting in producing wells, U.S. patent No. 5,243,562, 7 September 1993.

[2] Wittrisch C., Laurent J. and Naville C. (1988), Process and device for installing seismic sensors inside a petroleum production well, U.S. patent No. 4,775,009, 4 October 1988. 


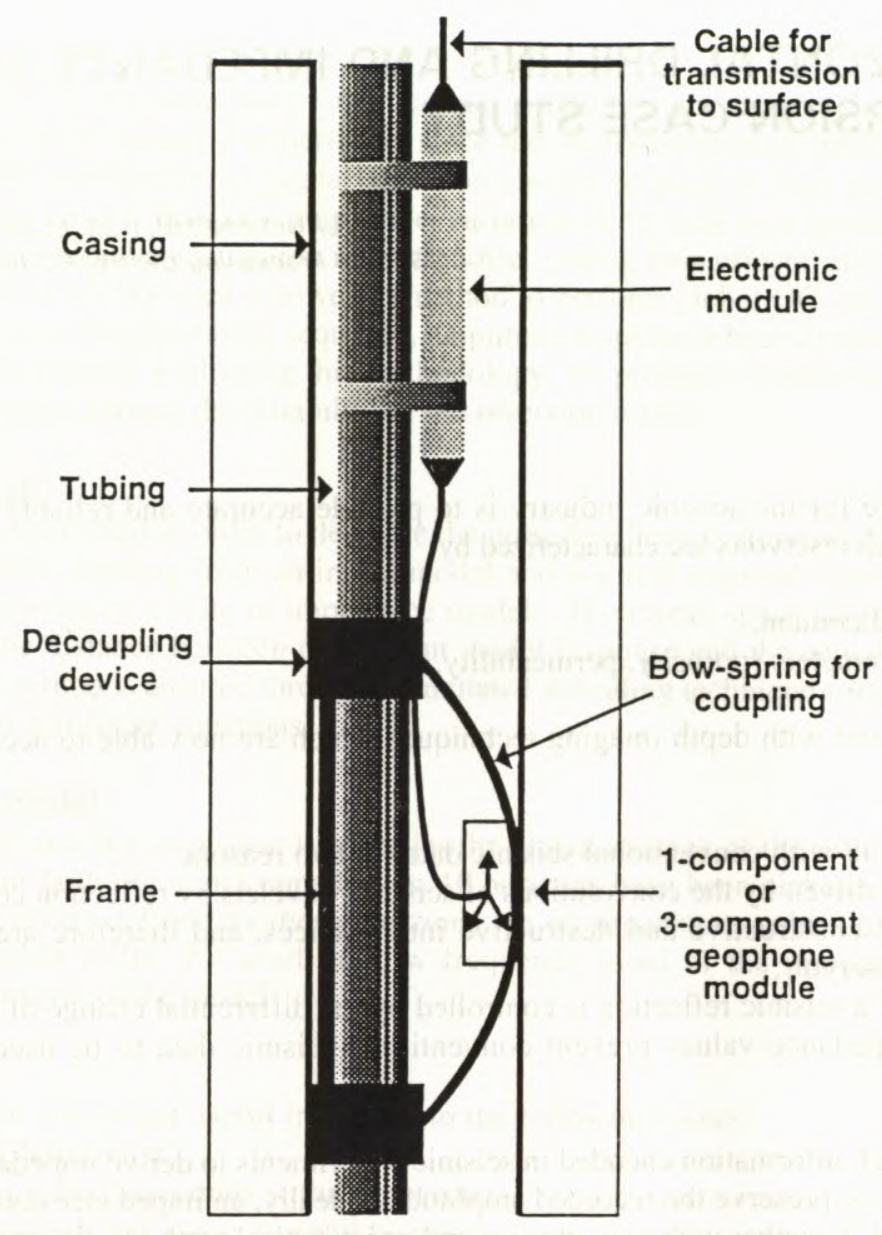

Figure 1: Diagram of an on-tubing Permanent Downhole Geophone

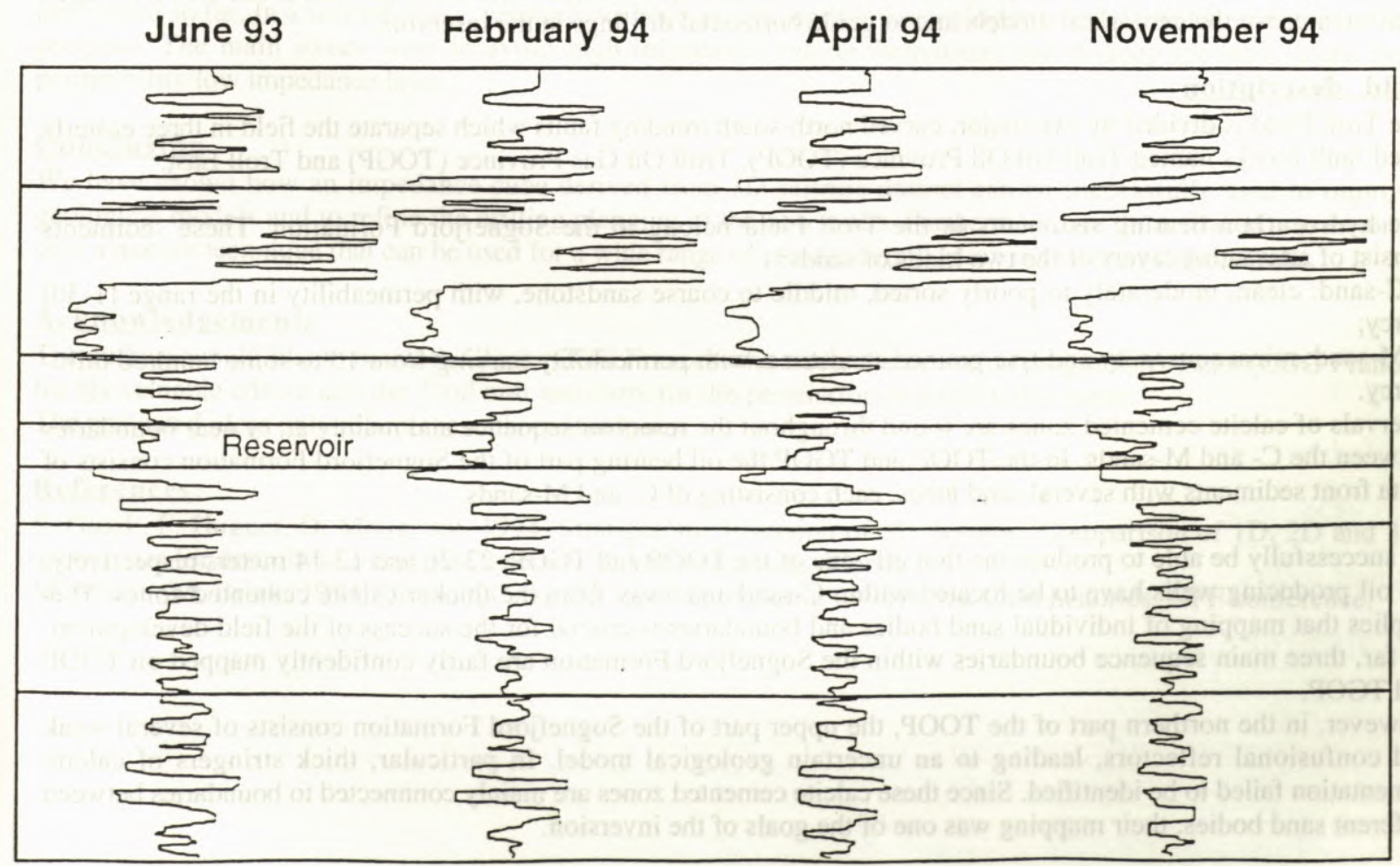

Figure 2: Impedance logs after 1D stratigraphic inversion from VSP data 